JOURNAL

of Health Inequalities

\title{
Stefania Jabłońska - some personal recollections
}

\author{
Harald zur Hausen, Ethel-Michele de Villiers \\ German Cancer Research Center, Heidelberg, Germany
}

ADDRESS FOR CORRESPONDENCE: Harald zur Hausen, German Cancer Research Centre, Im Neuenheimer, Feld 28069120 Heidelberg, Germany, e-mail: zurhausen@dkfz-heidelberg.de

The sad news that Stefania Jabłońska passed away in May this year touched a large number of her friends and colleagues. We all knew that her health deteriorated in recent years and we regretted that we had no opportunity to visit her during this difficult period. With Stefania, one of the great pioneers in dermato-oncology and tumour virology has gone. In particular, we have been intrigued by her elegant studies on epidermodysplasia verruciformis (EV), which represented a first milestone in studying the potential oncogenicity of human papillomaviruses (HPV). We contacted her in the early 1970 s, requesting a possible collaboration on EV-viruses, which she had started earlier with Gérard Orth in Paris. The latter collaboration successfully established a novel subgroup of HPVs.

Up to the end of the 1970s and the beginning of the 1980s we met Stefania at some of the early HPV meetings, one of them organised in Heidelberg. These events, commonly attended by not more than 25-30 participants, were all very interactive, with Stefania as a very helpful and eloquent member.

In 1985, jointly with Gérard Orth, she received the Robert-Koch-Award. This was a happy and joyful reunion with several of her friends in Germany. A year later,
Stefania invited Gérard Orth and us on a tour in Southern Poland and to Cracow. This happened exactly on the day of the Chernobyl accident. Under the difficult political circumstances of that time it was an extremely well organised and highly memorable tour which none of us will forget.

Stefania Jabłońska was an internationally highly reputed dermatologist and scientist, always active and helpful, and a caring and thoughtful friend. For all of us her death leaves us in grief and mourning. We will keep her vivid in our memory.

\section{DICLOSURE}

Authors report no conflict of interest.

Professor Harald zur Hausen was awarded the Nobel Prize in Physiology or Medicine in 2008 "for his discovery of human papilloma viruses causing cervical cancer". His research on the association between infectious agents and cancer made it possible to develop a vaccine against cervical cancer - one of the most common cancers in women. Professor zur Hausen continues his work at the German Cancer Research Center (DKFZ) in Heidelberg, Germany, of which he was Director for many years. 